\title{
EL RETORNO DEL DERECHO ADMINISTRATIVO
}

\author{
MIGUEL SÁNCHEZ MORÓN' \\ Universidad de Alcalá \\ miguel.sanchez@uah.es
}

\author{
Cómo citar/Citation \\ Sánchez Morón, M. (2018). \\ El retorno del derecho administrativo. \\ Revista de Administración Pública, 206, 37-66. \\ doi: https://doi.org/10.18042/cepc/rap.206.02
}

\section{Resumen}

Desde finales del siglo xx se multiplicó la creación de entidades del sector público regidas por el derecho privado en su organización o al menos en su actuación, fenómeno que fue descrito como la «huida del derecho administrativo». La legislación reciente, por diferentes razones, dispone que dichas entidades se sujeten de nuevo al derecho administrativo y su sistema de garantías en una pluralidad de aspectos. Este artículo explica esta última evolución y sus causas y extrae algunas consecuencias sobre la teoría y la aplicación del derecho administrativo.

\section{Palabras clave}

Derecho administrativo; actos y contratos administrativos; régimen jurídico de las entidades del sector público.

\section{Abstract}

Since the end of 20th Century the number of non-departmental public bodies regulated by Private Law instead of Public Law was substantially increasing, to the point that some authors describe the situation as an " escape from the Administrative Law ». For several reasons, recent legislation again requires for the

1 Catedrático de Derecho Administrativo. Una versión de este trabajo se publicará en el libro homenaje al profesor Ángel Menéndez Rexach. 
subjection of these public bodies to Administrative Law. This article explains that latest evolution and some of its consequences for legal theory and practice.

\section{Keywords}

Administrative Law; administrative decisions and public contracts; public bodies and publics companies legal regime. 


\section{SUMARIO}

I. SOBRE EL ORIGEN Y LAS CAUSAS DE LA HUIDA DEL DERECHO ADMINISTRATIVO. II. SU REFLEJO EN LA LEGISLACIÓN GENERAL Y ALGUNAS CONSECUENCIAS. III. UNA INVERSIÓN DE TENDENCIA. LA INFLUENCIA DEL DERECHO EUROPEO. IV. LOS EFECTOS SOBRE LA CUESTIÓN DE LA CRISIS PRESUPUESTARIA. V. OTRAS MANIFESTACIONES EN LA LEGISLACIÓN RECIENTE. VI. LA APORTACIÓN DOGMÁTICA DE LA NUEVA LEY DE CONTRATOS DEL SECTOR PÚBLICO. VII. PARA CONCLUIR.

\section{SOBRE EL ORIGEN Y LAS CAUSAS DE LA HUIDA DEL DERECHO ADMINISTRATIVO}

Desde el inicio de la década de los noventa del pasado siglo se convirtieron en un lugar común las alusiones a la "huida del derecho administrativo». Casi todos los que por entonces usaron la expresión atribuyeron su hallazgo al profesor Clavero Arévalo, que en un artículo publicado en 1962 en Documentación Administrativa ${ }^{2}$ se había referido, en efecto, a la "huida», "evasión" o «emancipación» del derecho administrativo «general» a través de la creación de nuevas entidades públicas con personalidad propia, dotadas de un derecho «singular». La explicación de tal huida estaría sobre todo en la búsqueda de una mayor agilidad y flexibilidad en la gestión económica y en la actividad jurídica de tales entidades. Pero lo que al profesor Clavero preocupaba era que el derecho singular de cada entidad autónoma, habitualmente reducido en su contenido, abría un amplio espacio a la discrecionalidad y a la inseguridad jurídica, por lo que proponía más que nada aplicar a dichas entidades, supletoriamente, el derecho administrativo general, algo que entendía procedente en interpretación y aplicación de la Ley de Entidades Estatales Autónomas de

2 M. Clavero Arévalo (1962), «Personalidad jurídica, derecho general y derecho singular de las Administraciones autónomas», Documentación Administrativa, 58, págs. 13-36. 
1958 y también, en cierto modo, del Reglamento de Servicios de las Corporaciones Locales de 1955.

La mencionada expresión adquirió otro significado a finales del siglo, cuando se constató no solo que sectores importantes de la organización administrativa se habían ido separando del tronco de las administraciones generales o territoriales, sino que muchas de las nuevas entidades resultantes habían pasado a regirse en su actividad - y otras también en su organización interna - por el derecho privado, en mayor o menor medida y al menos de manera supletoria, excluyendo así la aplicación del sistema de garantías propio del derecho administrativo: la vinculación positiva a la ley, los límites de la discrecionalidad, la igualdad de los ciudadanos ante el poder público, el procedimiento administrativo y los recursos administrativos y contenciosos... Y ello por no hablar de la relajación del régimen presupuestario y de control económico-financiero interno en dichas entidades. Tales problemas se ponen de manifiesto, con preocupación, en un mismo número de la Revista de Administración Pública de 1991 por los profesores Garrido Falla ${ }^{3}$ y Sebastián Martín-Retortillo ${ }^{4}$, a los que sigue otro del profesor Sala Arquer publicado en la Revista Española de Derecho Administrativo en $1992^{5}$. Para este último, la huida del derecho administrativo es, en realidad, una huida del derecho; tesis contestada, a su vez, por el profesor Borrajo Iniesta en 1993 y en la misma revista ${ }^{6}$. Desde entonces la cuestión de la huida del derecho administrativo ocupa un espacio señalado en cualquier manual de la disciplina que se precie ${ }^{7}$, suele abordarse sin falta en cualquier memoria o exposición de los proyectos docentes de la misma que se estilan en los concursos de acceso a las plazas de profesores universitarios y se menciona o analiza en numerosas monografías de diferente objeto.

Conviene precisar, no obstante, los términos del problema. A tal efecto no está de más recordar que la utilización de derecho privado por la Administración en sus relaciones con terceros está en el origen mismo del régimen

3 F. Garrido Falla (1991), «Privatización y reprivatización», Revista de Administración Pública, 126, págs. 7-26.

4 S. Martín-Retortillo (1991), «Las Empresas Públicas: reflexiones del momento presente», Revista de Administración Pública, 126, págs. 63-132.

5 J. M. Sala Arquer (1992), «Huida al Derecho privado y huida del Derecho», Revista Española de Derecho Administrativo, 75, págs. 399-413.

6 I. Borrajo Iniesta (1993), "El intento de huir del Derecho administrativo», Revista Española de Derecho Administrativo, 78, págs. 233-249.

7 Empezando por el Curso de Derecho Administrativo de E. García de Enterría y T. R. Fernández Rodríguez; véase el tomo I de la última edición de esta obra, $18^{a}$, CivitasThomson Reuters, 2017 (págs. 445-460). 
administrativo, cuando se distinguen los actos de autoridad de los actos de gestión. Los primeros, por los que la Administración manifiesta su condición de poder público, actos unilaterales y vinculantes, se regulan «naturalmente» por el derecho administrativo; los segundos no necesariamente, sino solo cuando la ley lo prevé ${ }^{8}$. Será con posterioridad, bajo el influjo de la Escuela del Servicio Público, cuando se considere que también esos otros actos llamados de gestión — por ejemplo, los de adjudicación y ejecución de contratos públicos- se han de regir por el derecho administrativo, ya que constituyen igualmente el ejercicio de una función pública, finalizada a la tutela de los intereses generales y sometida a reglas exorbitantes para garantizar su correcto ejercicio. De ahí, por ejemplo, la construcción dogmática de la figura del contrato administrativo, tanto en el derecho francés como en el nuestro. Aun así, la Administración quedó sometida al derecho privado en algunos tipos de relaciones jurídicas, como, por ejemplo, la gestión de sus bienes patrimoniales — dejando de lado los actos «separables» de adquisición y enajenación de esos bienes y algunos privilegios - y en los supuestos de contratación de personal en régimen laboral, que poco a poco se fueron extendiendo.

Por lo demás, la Administración siempre pudo intervenir en el tráfico jurídico privado, si lo demandaba la defensa de los intereses nacionales, creando o adquiriendo empresas industriales o mercantiles o participando en su capital, empresas lógicamente sujetas a derecho privado por razón de sus actividades. Esta actividad industrial y mercantil de las administraciones públicas, que en nuestro caso se inicia en los años veinte del pasado siglo" nunca se consideró sujeta a derecho administrativo, con independencia también de los actos «separables» de creación de sociedades y de adquisición y enajenación de activos empresariales. Antes bien, a partir de un cierto momento su sujeción a derecho privado quedó incluso confirmada por la necesidad de evitar privilegios o situaciones de ventaja que pudieran falsear la libre competencia entre empresas públicas y privadas, tal como prescribe hoy el Tratado de Funcionamiento de la Unión Europea (art. 107.1; antes 87.1 TCE).

8 Sobre la distinción entre actos de autoridad y actos de gestión, que se debe a los primeros tratadistas franceses de derecho administrativo (Aucoc, Laferrière...), puede verse una clara explicación en S. Muñoz Machado (2015), Tratado de Derecho Administrativo y Derecho Público General, I, 4a ed., BOE (págs. 44-49). De manera algo más extensa trata también la cuestión D. Canals i Ametller (2003), El ejercicio por particulares de funciones de autoridad. Control, inspección y certificación, Granada: Comares (págs. 255-263).

9 La primera empresa pública de naturaleza industrial o mercantil en nuestro país es CAMPSA (Compañía Arrendataria del Monopolio de Petróleos, S.A.), creada en 1926. 
Pero lo que a finales del siglo XX preocupaba a los autores mencionados no era precisamente una eventual expansión de esta actividad industrial o mercantil del Estado y otras administraciones públicas. En realidad es en esa última década del siglo cuando, en virtud de los principios de libertad económica y de las políticas antimonopolio impulsadas desde las instituciones europeas, se inicia el desmantelamiento del patrimonio industrial del Estado, que había llegado a ser muy importante ${ }^{10}$. Lo que sucede es que, al mismo tiempo, las fórmulas de personificación propias del derecho privado — sociedades mercantiles, fundaciones, en menor medida asociaciones - se empezaron a utilizar para la realización de funciones públicas hasta entonces sometidas a derecho administrativo y se aceptó por el legislador que algunos entes públicos pudieran ejercer su actividad propia con sujeción a derecho privado.

Estas nuevas posibilidades legales se fueron abriendo camino paulatinamente. Primero la Ley General Presupuestaria de 1977 facilitó la tarea al diferenciar (art. 4) dentro de los organismos autónomos los de carácter administrativo y los de carácter comercial, industrial, financiero o análogos, dotados estos últimos de un régimen presupuestario y de control más flexible; además, esa misma ley (arts. 6.1 y 2) equiparó el régimen económico-financiero de las entidades de derecho público que hubieran de ajustar por ley sus actividades al derecho privado - lo que veinte años después la LOFAGE denominaría entidades públicas empresariales - al de las sociedades mercantiles estatales. Más aún, su texto refundido de 1988 admitía (art. 6.5) que el resto de los entes del sector público no incluido en ninguna de esas categorías — entes públicos, pues, de naturaleza especial- se regiría por su normativa específica ${ }^{11}$. A partir de entonces y en virtud de normas incluidas muchas veces en las leyes anuales de presupuestos del Estado (o en las llamadas «leyes de acompañamiento» de los mismos), algunos organismos autónomos asumieron el carácter comercial, industrial, financiero o análogo, incluso si sus actividades esenciales eran típicamente administrativas, como fue el caso de las Confederaciones Hidrográficas; otros pasaron a equipararse a las sociedades estatales — por ejemplo, el Instituto de Crédito Oficial— o acabaron transformándose en verdaderas sociedades mercantiles de capital público — por ejemplo, Correos y Telégra-

10 Un hito al efecto es la Ley 5/1995, de 23 de marzo, de enajenación de participaciones públicas en determinadas empresas y la contemporánea supresión del Instituto Nacional de Industria (INI), sustituido por la Agencia Industrial del Estado y por la SEPI (Sociedad Estatal de Participaciones Industriales) por Real Decreto Ley 5/1995, de 16 de junio.

11 El citado art. 6.5 procedía de la Ley 33/1987, de 23 de diciembre, de Presupuestos Generales del Estado. 
fos ${ }^{12}$ - ; y se crearon otros entes especiales al amparo del citado art. 6.5 del texto refundido de la LGP de 1988 y sucesivas - Instituto Cervantes, Museos del Prado y (posteriormente en 2011) Reina Sofía, etc.-, básicamente sometidos a derecho privado en el ejercicio de su actividad y en el régimen de su personal, conforme a las leyes de creación y a sus respectivos estatutos.

Poco después, la organización de los grandes eventos de 1992 - Juegos Olímpicos de Barcelona y Expo de Sevilla - fue la ocasión para crear algunas entidades de gestión con forma de sociedad anónima - Holding Olímpico, S.A. (HOLSA) y la Sociedad EXPO 92- a las que se transfirieron cuantiosos recursos de los presupuestos del Estado, con el encargo de contratación de las obras públicas y servicios necesarios ${ }^{13}$. De esta manera podían esquivarse los trámites del procedimiento de contratación pública, entonces aplicables solo a los contratos celebrados por las administraciones públicas en sentido estricto (incluidos los organismos autónomos administrativos), pudiendo adjudicar tales contratos de finalidad eminentemente pública a la manera de un empresario privado. El invento fue rápidamente imitado. Enseguida la Generalitat de Cataluña creó la entidad Gestió de Infraestructures, S.A. ${ }^{14}$, para la contratación de algunas obras relacionadas con los Juegos Olímpicos, pero después utilizada para cualesquiera otras obras públicas de la comunidad autónoma; y el ejemplo cundió, pues muchas otras administraciones autonómicas y locales crearon entidades similares con los mismos fines. Incluso el Estado constituyó algunas sociedades mercantiles de capital público para la gestión de infraestructuras o del patrimonio ${ }^{15}$.

Más aun, cuando se empezó a plantear la necesidad de mantener dentro de ciertos límites el déficit y la deuda pública en los Estados de la Unión Económica y Monetaria europea y se aprobó en nuestro país una primera legislación de estabilidad presupuestaria — la Ley 18/2001, de 12 de diciembre-, algunos gobiernos autonómicos y locales entendieron que podían eludir los límites legales de su endeudamiento mediante la creación de sociedades mercantiles de capital público con capacidad de acceso a los mercados financieros, a las que encargar la gestión y contratación de costosos programas de obra pública. Las supuestas imprecisiones o lagunas del sistema europeo de contabi-

12 Recuérdese que, en pocos años, el servicio de Correos pasó por diferentes fórmulas organizativas: organismo autónomo de carácter comercial (1990), entidad pública empresarial (1997) y, finalmente, sociedad mercantil estatal, desde la Ley de 29 de diciembre de 2000.

13 Me remito sobre ello a E. Malaret García (1993), Público y privado en la organización de los Juegos Olimpicos de Barcelona, Madrid: Civitas.

14 Hoy Infraestructures de Catalunya, S.A.U.

15 SEIPSA, SEITT, SEIASA, SEGIPSA... 
lidad entonces vigente (SEC-95), interpretadas de manera laxa, parecían permitirlo, siempre que se clasificase a tales entidades como empresas y no como parte del sector de las «administraciones públicas» a efectos contables, de manera que su deuda no consolidara como propia de la administración matriz. Un ejemplo característico de esta estrategia fue la creación por la Comunidad de Madrid de la entidad MINTRA (Madrid Infraestructura del Transporte, S.A.), a la que se encomendó la contratación de la importante ampliación de las líneas del Metro de Madrid, aparte de otras obras públicas.

Otra vía legal para escapar de la disciplina del régimen administrativo fue la creación de fundaciones del sector público, esto es, dotadas de un patrimonio fundacional aportado mayoritariamente con fondos públicos, aunque no en todas ellas la Administración asumió la mayoría de los puestos del patronato $^{16}$. Así lo permitió expresamente la Ley 30/1994, de 24 de noviembre, de fundaciones e incentivos fiscales a la participación privada en actividades de interés general (art. 6.4) y lo ratificó más claramente la Ley 50/2002, de 26 de diciembre, de Fundaciones (arts. 44 ss.). Ciertamente, no era esta una figura pensada para gestionar servicios públicos, pero con el tiempo una parte de las actividades y servicios dependientes de distintas administraciones territoriales en el sector cultural — teatros, museos, orquestas...- o en el de la investigación científica y técnica, en el de los servicios sociales y algunos servicios sanitarios o actividades de cooperación internacional al desarrollo acabaron por organizarse en forma de fundación. Todas las universidades públicas crearon también sus propias fundaciones para desempeñar funciones de extensión universitaria, culturales y de cooperación y, con fines diversos, lo mismo hicieron numerosos entes y empresas públicas. Es más, la Ley General de Subvenciones de 2003 (disposición adicional 16a) reconoció expresamente la capacidad de estas fundaciones públicas para acordar y otorgar «entregas dinerarias sin contraprestación» —es decir, subvenciones— relacionadas con su objeto, rigiéndose también en esta actividad por el derecho privado, aunque con la obligación de observar "los principios» de gestión de la propia ley.

En fin, y aparte de algunas otras experiencias singulares, un vehículo más para la gestión de actividades y servicios públicos con sujeción al derecho privado, frecuentemente utilizado, ha sido la creación de consorcios entre distintas administraciones públicas, a veces con participación de entidades privadas. Hasta hace muy poco los consorcios administrativos han carecido de una mínima regulación legal, más allá de la habilitación para crearlos, de

16 Esto último, por cierto, ya no es posible en las fundaciones del sector público estatal, conforme al art. 135 LRJSP de 2015, pero sí lo era antes de esta ley y así sucedía en algunos casos, por ejemplo, la Fundación Tripartita para la Formación en el Empleo (hoy FUNDAE). 
manera que se han constituido con gran discrecionalidad y se han regido casi de manera exclusiva por lo dispuesto en sus respectivos estatutos, que en la mayor parte de los casos y aspectos se remitían al derecho privado ${ }^{17}$.

Todas estas oportunidades de —llamémoslas así- ingeniería jurídica surgieron por lo demás en una época en las que se estaba desarrollando la organización de las nuevas administraciones autonómicas y se había reforzado la autonomía organizativa de las entidades locales. Unas y otras han hecho uso de tales fórmulas de huida del derecho administrativo de manera reiterada (por no decir abusiva), más aun que la Administración del Estado, con la consecuencia de la aparición de varios miles de entidades del sector público cuya actividad se rige sustancialmente por el derecho privado, entre sociedades, fundaciones, consorcios, entidades públicas empresariales, entes de régimen especial y algunas otras figuras afines ${ }^{18}$.

\section{SU REFLEJO EN LA LEGISLACIÓN GENERAL Y ALGUNAS CONSECUENCIAS}

La huida del derecho administrativo como fenómeno o tendencia jurídica entroncaba directamente, en nuestro país como en otros, con las teorías de new public management, tan en boga por aquella época, que partían de una crítica profunda de la burocracia pública. La ineficacia de la acción burocrática, debida en gran parte a la lentitud de los procedimientos de decisión y a los controles administrativos previos además de a la rigidez del régimen funcionarial, debía ser combatida abandonando ese modelo, propio del sistema de dominación de las élites políticas y de los cuerpos superiores de funcionarios, para optar siempre que fuera posible por otro régimen de decisión más parecido al de la empresa privada. Ciertamente esta transformación de los modos de gestión no es apropiada para la "administración de autoridad», aquella que aprueba normas generales y actos de imperio que limitan la esfera de libertad de los individuos —órdenes, sanciones, autorizaciones, etc.—, pero sí para otro tipo de actividades, en buena medida coincidentes con los que en

17 Puede verse sobre dicha situación, anterior a las últimas reformas legales, y en sentido muy crítico, Tribunal de Cuentas, Informe de fiscalización de los consorcios de ámbito local, núm. 1.016, de 23 de diciembre de 2013.

18 Así se deduce de los datos del Inventario de Entidades del Sector Público Estatal, Autonómico y Local gestionado por la IGAE, que a principios de 2018 registra casi 2.200 sociedades mercantiles públicas, alrededor de 900 fundaciones y otros tantos consorcios y más de 100 entidades públicas empresariales, sin contar otros entes públicos de régimen especial. 
el siglo xix se denominaron «actos de gestión». En estos casos, lo procedente era reconocer a los gestores públicos un margen de autonomía o capacidad de decisión propia en el ejercicio de su competencia y en el empleo de los recursos a su disposición; sustituir los controles preventivos de legalidad y del gasto por otros a posteriori; y agilizar al máximo los procedimientos decisionales. Nada mejor para ello que utilizar el derecho propio de las empresas, esto es, el derecho privado, tanto en las relaciones con los «clientes» (en realidad los usuarios de los servicios y los ciudadanos destinatarios de la acción pública) como con los "proveedores» (es decir, los contratistas) y también en el ámbito de las relaciones de empleo.

La legislación general reflejó cabalmente esta tendencia. Así, la LOFAGE de 1997, en su disposición adicional 12a , se limitaba a establecer en relación con las sociedades mercantiles estatales su sujeción «íntegra» a derecho privado, salvo lo dispuesto en la normativa presupuestaria, contable, patrimonial, de control financiero y de contratación, con la única limitación de no poder dichas sociedades disponer de facultades que impliquen «ejercicio de autoridad pública». De la misma manera, la Ley de Fundaciones de 2002, que también prohibía a las fundaciones del sector público estatal ejercer potestades públicas, se remitía para el ejercicio de sus actividades propias a lo dispuesto en la propia ley, no al derecho administrativo, sin perjuicio de las disposiciones en materia presupuestaria, contable y de auditoría de la Ley General Presupuestaria, que tanto para las fundaciones como para las sociedades establece un régimen de control económico-financiero a posteriori y más flexible que el de las administraciones públicas, y con la vaga obligación de respetar los principios de publicidad, concurrencia y objetividad en la contratación — «salvo que la naturaleza de la operación a realizar sea incompatible con estos principios»— y en el otorgamiento de subvenciones — "siempre que los recursos procedan del sector público estatal»—, así como de respetar los principios de igualdad, mérito y capacidad y publicidad en la selección de su personal (art. 46).

En el mismo sentido se pronunciaba el resto de la legislación administrativa de la época en relación con la actividad de las sociedades mercantiles públicas: en concreto, la Ley de Contratos de las Administraciones Públicas de 1995 (disposición adicional 6a) y la Ley 33/2003, de Patrimonio de las Administraciones Públicas (arts. 166.2 y 167.2); o en relación con la actividad de las fundaciones y así la citada Ley 18/2003, General de Subvenciones (disposición adicional 16a). También en coherencia con ello, aunque con mayor retraso, el Estatuto Básico del Empleado Público de 2007 estableció que las entidades del sector público no incluidas en su ámbito de aplicación -básicamente sociedades y fundaciones- debían aplicar los principios generales de esa ley sobre selección de personal, aunque no sus preceptos concretos (salvo 
la reserva de puestos para personas con discapacidad) y las reglas del código de conducta de los empleados públicos (disposición adicional 1a); pero nada más.

La jurisprudencia, por su parte, sin merma de la aplicación de todas esas normas legales, vino a reconocer un amplio margen de libertad de las distintas administraciones - y de los legisladores - para elegir las formas de organización de los servicios y funciones de su competencia ${ }^{19}$.

Sin duda, la huida hacia el derecho privado permitía agilizar los trámites de la contratación, la selección de personal —o el despido, en su caso- y el otorgamiento de ayudas o subvenciones, entre otras decisiones. También permitía negociar las condiciones de empleo de trabajadores y directivos sin el corsé del régimen retributivo de los funcionarios y las correspondientes restricciones presupuestarias. Facilitaba incluso la constitución por las entidades del sector público de filiales o nuevas sociedades de objeto más específico e inclusive la inversión de sus recursos en otras empresas, públicas o privadas, o en valores financieros. Todo ello con gran discrecionalidad y menor publicidad. En fin, last but not least, permitía eludir la gravosa fiscalización previa del gasto y adoptar decisiones de gestión económico-financiera con mayor rapidez. En la práctica suponía una especie de desdoblamiento de la personalidad de las administraciones generales para poder actuar con mayor libertad, máxime si se tiene en cuenta que los miembros de los órganos de gobierno o consejos de administración o de dirección de sociedades y consorcios y de los patronatos de las fundaciones públicas son en gran medida personas que ostentan un alto cargo en los gobiernos y administraciones de que dependen o bien otras libremente nombradas (y destituibles) por ellas.

Pero otra consecuencia, como temían los críticos de la huida del derecho administrativo, ha sido un mayor descontrol del gasto, un extendido favoritismo en la adjudicación de contratos, en el reclutamiento de personal o en el reparto de ayudas y en determinados casos - ciertamente no generalizables-, episodios de corrupción, que la opacidad de la gestión, la práctica ausencia de controles internos de legalidad y la debilidad, impuntualidad o

19 Baste como muestra la STS de 16 de abril de 2001 (rec. núm. 508/1998), que resuelve el recurso contra acuerdo del Consejo de Ministros por el que se crea la Sociedad «Aguas del Júcar, S.A.». Declara el Tribunal Supremo en ella que se trata de «una decisión de política económica que compete exclusivamente al Consejo de Ministros»; que «la decisión es autónoma como lo es la que se toma por los particulares en la constitución de una sociedad civil o mercantil»; y que «es, por tanto, enteramente discrecional su potestad y libre la facultad de crear por sí una sociedad [...] como legítimo hubiera sido acudir a cualquier otro medio de gestión directa para la ejecución de obras hidráulicas, de entre las varias que le proporciona el Ordenamiento». 
ineficacia de los controles externos subsistentes han venido a facilitar. Basta constatar que algunos de los casos de corrupción (o presunta corrupción) más sonados descubiertos en los últimos años están relacionados con el funcionamiento de entidades del sector público sujetas a derecho privado. Así, por ejemplo, el caso ACUAMED, que es una sociedad estatal dedicada sobre todo a la contratación de obras hidráulicas; el caso del Palau de la Música Catalana, consorcio administrativo sujeto a derecho privado; o el que ha afectado al Canal de Isabel II, una entidad pública que ha creado o adquirido numerosas sociedades mercantiles filiales en España e Iberoamérica.

Ahora bien, no todos los casos son iguales. La creación de entidades instrumentales sometidas a derecho privado puede tener sentido y justificación objetiva en algunos de ellos; en particular tratándose de entidades que ofrecen servicios al mercado mediante precios o tarifas - por ejemplo, RENFE- o que deben gestionar servicios en un entorno de competencia - la Sociedad Correos y Telégrafos podría ser una de ellas - o bien cuando se precisa una cierta flexibilidad en la contratación y gestión de personal — por ejemplo, los directores y profesores de una orquesta pública, los directivos, conservadores y restauradores de un museo, la formación de grupos de investigación atractivos para científicos eminentes, etc.- - No la tiene si lo que se persigue es más que nada eliminar controles internos, sustituyendo a los funcionarios en el ejercicio de funciones públicas tan características como la adjudicación de contratos o el otorgamiento de ayudas o subvenciones con cargo a los recursos públicos. Por eso, y teniendo en cuenta la mencionada libertad organizativa de los medios de gestión, algunos venimos propugnando desde hace tiempo que, sea cual sea el tipo de entidad que las ejerza, el régimen de esas funciones se someta en todo caso a los principios y reglas de derecho administrativo.

\section{UNA INVERSIÓN DE TENDENCIA. LA INFLUENCIA DEL DERECHO EUROPEO}

Esta revisión de tendencia se viene concretando, en efecto, en una parte de la legislación reciente, hasta el punto de que podíamos hablar de un cierto «retorno del derecho administrativo»; con la debida cautela, por supuesto, ya que no es una vuelta al pasado sin más, ni excluye toda aplicación del derecho privado por las entidades del sector público y porque no es posible saber si estamos ante un cambio irreversible.

Una parte de esa legislación viene determinada por el derecho de la Unión Europea o al menos encuentra en él su origen e influencia, lo que augura una mayor estabilidad de sus normas. Otra parte parece entroncar con las medidas de reacción frente a la crisis económica y la necesidad de observar 
los principios de estabilidad presupuestaria y sostenibilidad financiera en el conjunto del sector público ${ }^{20}$. Otras reformas legales, en fin, son el resultado de la voluntad del legislador interno, pero no siempre han contado con un amplio consenso entre los grupos parlamentarios o bien mantienen cierta ambigüedad en sus términos, lo que puede condicionar su futuro y su aplicación efectiva.

La primera reacción frente a la huida del derecho administrativo se produce, en efecto, en el ámbito de la contratación pública y se debe a la necesidad de aplicar las directivas europeas en la materia, que ya en 1992 y $1993^{21}$ definían los organismos de derecho público como todos aquellos entes u organismos dotados de personalidad jurídica y creados para satisfacer necesidades de interés general que no tengan carácter industrial o mercantil, cuya actividad esté mayoritariamente financiada por una administración u otro organismo público, o bien estén sometidos a supervisión de una u otro, o bien tengan órganos de administración, supervisión o dirección cuyos miembros sean nombrados en su mayoría por el Estado, una administración territorial u otro organismo público. Y ello con independencia de cuál fuera la forma jurídica - pública o privada - de personificación de tales organismos. Como la entonces vigente Ley de Contratos de las Administraciones Públicas de 1995 no cumplía con esas disposiciones de las directivas de contratos en lo relativo a su ámbito subjetivo de aplicación, el Tribunal de Justicia de la Unión Europea dictó varias sentencias contra España declarando tal incumplimiento: SSTJUE de 15 de marzo de 2003, Comisión/España (C-214/00), de 16 de octubre de 2003, Comisión/España (C-283/00, sobre adjudicación de contratos por la sociedad estatal SIEPSA) y 13 de enero de 2005, Comisión/España (C-84/03).

A consecuencia de esas sentencias hubo de modificarse dicha Ley de Contratos de las Administraciones Públicas, lo que se hizo sucesivamente por Ley 62/2003, de 30 de diciembre, y por Real Decreto Ley 5/2005, de 11 de marzo, para incluir como poderes adjudicadores de contratos públicos sujetos a aquella ley también a las entidades consideradas como organismos de derecho público por las directivas, aunque se tratara de sociedades mercantiles, fundaciones públicas, entidades públicas empresariales u otras sometidas a

20 A estas dos causas se ha referido ya, en sentido similar al que se expresa en estas páginas C. Chinchilla Marín (2016), «El derecho de la Unión Europea como freno a la huida del derecho administrativo", Revista de Administración Pública, 200, págs. 361383.

21 Directiva 92/50/CEE, sobre adjudicación de los contratos públicos de servicios, Directiva 93/36/CEE, sobre adjudicación de los contratos públicos de suministros, y Directiva 93/37/CEE, sobre adjudicación de los contratos públicos de obras. 
derecho privado. Ahora bien, tal ampliación del ámbito subjetivo se acordó exclusivamente en lo relativo a la adjudicación de los contratos de obras, servicios y suministros de elevada cuantía regulados por las directivas europeas. Posteriormente, como es sabido, la Ley 30/2007, de 30 de octubre, de Contratos del Sector Público reguló de manera más sistemática su ámbito de aplicación (art. 3), incluyendo la consideración como "poderes adjudicadores» de contratos públicos a todos aquellos entes que cumplieran los requisitos establecidos por las directivas, aunque no tuvieran la calificación de administraciones públicas o de entes u organismos públicos conforme al derecho interno. No obstante, los efectos de esa regulación se limitaban también a los procedimientos de adjudicación de los contratos «sujetos a regulación armonizada", es decir, los de obras, suministros y servicios que superaran los umbrales económicos fijados en aplicación de las directivas, y poco más (arts. 13 a 17). Para el resto de los contratos, la LCSP de 2007 se ceñía a establecer que los poderes adjudicadores que no tuvieran la condición de administraciones públicas, así como las demás entidades del sector público que no tuvieran carácter de poderes adjudicadores (en este caso para la totalidad de sus contratos), debían someter en todo caso su actividad contractual a los principios de publicidad, concurrencia, transparencia, confidencialidad, igualdad y no discriminación y aprobar unas instrucciones internas sobre el procedimiento de contratación para garantizar tales principios.

En orden a la recuperación de la aplicación del derecho administrativo por las entidades privadas del sector público y otros entes públicos sujetos a derecho privado en su actividad, la regulación de la LCSP de 2007 (y sus precedentes) fue un primer paso, aunque nada más, ya que la voluntad del legislador fue atenerse estrictamente a los mandatos literales de las directivas europeas sin ir más allá de lo que su espíritu preconizaba. Sin embargo, la introducción del recurso especial en materia de contratación, exigido también por la normativa europea en todos los casos de adjudicación de contratos públicos regulados por ellas ${ }^{22}$, supuso que el legislador español admitiera la interposición de un recurso inequívocamente administrativo contra decisiones adoptadas por sociedades mercantiles de capital público y fundaciones públicas, lo que de alguna manera implicaba reconocer, en un plano conceptual, que tales entidades están sometidas a derecho administrativo cuando

22 La introducción de un recurso ágil y efectivo contras los actos de preparación y adjudicación de los contratos viene exigida, como es sabido, por la Directiva 89/665/ CEE, modificada por la Directiva 2007/66/CE. La introducción del recurso especial en materia de contratos en nuestro ordenamiento tuvo lugar, tras la fallida regulación de la LCSP de 2007, por la Ley 34/2010, de 5 de agosto, después integrada en el texto refundido de la LCSP de 14 de noviembre de 2011. 
ejercen una "función pública» definida como tal por las leyes, como es la adjudicación de determinados contratos públicos. Y ello con la consecuencia de que, al conocer de la eventual impugnación de las resoluciones de los tribunales administrativos de recursos contractuales, la Jurisdicción ContenciosoAdministrativa puede controlar también, de manera indirecta, una parte de la actuación de aquellas sociedades y fundaciones; una idea esta que, por cierto, ya había vislumbrado, aunque sin mayor precisión ni desarrollo, la Ley de la Jurisdicción Contencioso-Administrativa de $1998^{23}$.

La influencia del derecho de la Unión Europea en el asunto de que aquí se trata no se limita, en cualquier caso, a la legislación de contratos. De alguna manera dicha influencia se percibe por lo menos en otros dos aspectos. El primero alude a las consecuencias que tiene la reforma del sistema europeo de cuentas nacionales y regionales, que se concreta en el denominado SEC-2010, aprobado por el Reglamento (UE) 549/2013, del Parlamento Europeo y del Consejo, de 21 de mayo de 2013. Si ya con anterioridad a esta norma podía adivinarse la irregularidad que supone intentar esconder o disfrazar el incremento de la deuda pública atribuyéndola formalmente a entidades instrumentales de naturaleza jurídica privada, ahora no cabe ya ambigüedad o duda alguna al respecto. Solo aquellas entidades del sector público que puedan ser consideradas "productores de mercado", básicamente porque se financian mayoritariamente y de manera estable con ingresos procedentes de la entrega de bienes o la prestación de sus servicios, se incluyen a efectos de contabilidad en el subsector de las «sociedades no financieras públicas» (S.11001). Las demás entidades del sector público, cualquiera que sea su forma de personificación, se integran en el sector de las «administraciones públicas» $(\mathrm{S} .13)^{24}$. Su deuda computa, pues, como deuda pública ${ }^{25}$.

23 La LJCA de 1998 dejaba abierta la puerta al recurso contencioso contra actos de poderes adjudicadores de contratos públicos, al disponer en su art. 2.b) la extensión del orden jurisdiccional contencioso-administrativo al conocimiento de las cuestiones relacionadas con «los actos de preparación y adjudicación de los demás contratos [no administrativos] sujetos a la legislación de contratación de las Administraciones Públicas», lo que no significaba solamente actos de estas mismas administraciones. El espíritu de la norma iba más allá de esto último, en sintonía con el artículo 2.d), que se refiere a la posibilidad de enjuiciar directamente en esa vía contenciosa actos de los concesionarios de servicios públicos — de empresas privadas, pues— que impliquen el ejercicio de potestades administrativas conferidas a los mismos. Pero para la concreción de dicha posibilidad se remitía a «la legislación sectorial correspondiente», que no ha desarrollado el supuesto.

24 Véase el capítulo 20 del SEC 2010, relativo al sector de las «administraciones públicas».

25 Quizá tenga algo que ver con ello la extinción de MINTRA en 2011. 
Un efecto de esta normativa europea se observa ya en la regulación de las entidades públicas empresariales que establece la Ley 4/2015, de Régimen Jurídico del Sector Público (LRJSP). No basta para crear o configurar este tipo de entidades que desarrollen actividades prestacionales o de producción de bienes o gestión de servicios susceptibles de contraprestación, como disponía la LOFAGE (art. 53.1), sino que además deben financiarse mayoritariamente con ingresos de mercado (art. 103.1 LRJSP). Por tal se entiende, precisamente, las que tengan la consideración de productor de mercado conforme al Sistema Europeo de Cuentas (art. 107.3). Esta modificación legal, que no tiene carácter básico aunque muy probablemente influirá en la legislación autonómica, obligará a revisar la calificación de algunas entidades públicas que aun hoy se denominan empresariales, pero se financian mayoritariamente con aportaciones presupuestarias ${ }^{26}$. No deja de ser significativo, sin embargo, que no se establezca expresamente la misma exigencia en la LRJSP para las sociedades mercantiles estatales.

Pese a ello, lo que se deduce implícitamente de esas normas europeas es que, dentro del sector público, solo tiene justificación el sometimiento a las reglas de derecho privado de aquellas actividades que se dirigen precisamente a la producción de bienes y servicios para el mercado; no en cambio a la prestación de servicios públicos, el ejercicio de potestades públicas o la realización de cualesquiera funciones materialmente públicas y financiadas total o mayoritariamente con recursos públicos. Pues en estos casos la utilización instrumental de sociedades o fundaciones es puramente artificial. Ciertamente, el derecho europeo reconoce una muy amplia autonomía de los Estados miembros para organizar sus actividades y servicios como prefieran, siempre que ello sea compatible con la correcta ejecución de la propia legislación europea. Pero, por esta misma razón, aquella autonomía organizativa encuentra cada vez mayores límites.

En fin y sin ir más lejos, una cierta influencia europea indirecta en la recuperación del derecho administrativo puede advertirse también en la legislación sobre transparencia y acceso a la información pública. La Ley 19/2013, de 9 de diciembre (LTBG), incluye dentro del ámbito de aplicación de sus normas sobre transparencia y derecho de acceso a la información pública a las sociedades mercantiles con más del 50 por ciento de su capital en mano pública, a las fundaciones del sector público y a las asociaciones constituidas por administraciones, organismos y entidades públicas

26 Téngase en cuenta, no obstante, que la propia LRJSP de 2005 da un plazo de tres años desde su entrada en vigor, que concluiría en octubre de 2019, para que las entidades y organismos que integran el sector público estatal se adapten al contenido de la misma (disposición adicional $4^{\circ}$ ). 
[art. 2.1.g), h) e i)]. Estas entidades de naturaleza jurídica privada tienen las obligaciones de publicidad activa que la ley establece y también son sujetos pasivos del derecho de acceso singularizado a la información que elaboren o adquieran en el ejercicio de sus funciones (art. 14). Con toda probabilidad, la amplitud de ese ámbito de aplicación se debe en parte a lo dispuesto por la precedente Ley 27/2006, de 18 de julio, por la que se regularon los derechos de acceso a la información, participación pública y acceso a la justicia en materia de medio ambiente, ley que a su vez transpuso a nuestro ordenamiento las directivas 2003/4/CE y 2003/35/CE, que incorporaron para la Unión y todos los Estados miembros las normas del Convenio de Aarhus de 25 de junio de 1998.

La Ley 27/2006 previó ya una reclamación ante la Administración pública competente en caso de que algunos de los derechos de información o participación ambiental fueran conculcados por personas o entidades dependientes de aquella (art. 21). Y asimismo hay que entender, pese a su falta de precisión terminológica, que es posible presentar la reclamación que regula el art. 24 de la LTBG contra las resoluciones expresas o presuntas que denieguen el acceso a una información pública, incluso si el sujeto obligado a responder a una solicitud de acceso es una entidad privada del sector público ${ }^{27}$. Al igual que en el caso del recurso especial en materia de contratación, se contempla aquí una reclamación administrativa contra decisiones de entidades del sector público con personificación jurídica de derecho privado, obligadas a aplicar en la materia normas de derecho administrativo.

27 Si bien está claro que el ámbito subjetivo de aplicación del título I de la LTBG, dentro del cual se regula el derecho de acceso, es aplicable a las sociedades mercantiles de capital mayoritariamente público, a las fundaciones del sector público y a las asociaciones que puedan constituir las administraciones y entidades del sector público (art. 2), la remisión que dicha Ley (art. 24.3) hace al régimen de los recursos administrativos de la Ley 30/1992 — hoy sustituida por la Ley 39/2015, de 1 de octubre (LPACAP) — para la tramitación de la reclamación administrativa ante el Consejo de Transparencia y Buen Gobierno puede suscitar alguna duda al respecto. Sin embargo, la disposición adicional $4^{a}$ de la LGTB se refiere como objeto de la reclamación prevista en el art. 24 a las «resoluciones dictadas por las Administraciones de las Comunidades Autónomas y su sector público», lo que da a entender que se trata también de «resoluciones» o decisiones sobre derecho de acceso adoptadas por las entidades privadas del sector público. Así lo entiende también C. Barrero (2014), en E. Guichot (coord.) et al., Transparencia, Acceso a la Información Pública y Buen Gobierno. Estudio de la Ley 19/2013, de 9 de diciembre, Tecnos, Madrid (p. 239). 


\section{LOS EFECTOS SOBRE LA CUESTIÓN DE LA CRISIS PRESUPUESTARIA}

La crisis económica y sus secuelas en el plano de la estabilidad presupuestaria y la sostenibilidad financiera es otro factor que repercute en la cuestión de que tratamos. Con independencia de la supresión, fusión o transformación de entidades del sector público que ha tenido lugar en los diferentes niveles territoriales de gobierno y administración, la legislación anticrisis ha adoptado unos criterios contrarios a la creación de nuevas entidades y, por lo que aquí más interesa, de preferencia por las formas de organización y gestión de los servicios basadas en el derecho administrativo. Es lógico, dado que, como se ha dicho, uno de los resultados de la huida del derecho administrativo en el marco de la organización administrativa ha sido una mayor dificultad para contener y controlar el gasto público.

La legislación del Estado manifiesta esta tendencia o preferencia tanto por lo que se refiere al sector público estatal como al local. Cronológicamente, este último fue el primero en recibirla, a través de la Ley 27/2013, de 27 de diciembre, de racionalización y sostenibilidad de la Administración Local (LRSAL). En virtud de ella, el art. 85.2.A) de la Ley de Bases del Régimen Local solo permite hacer uso de la gestión de servicios públicos locales a través de entidades públicas empresariales locales o de sociedades mercantiles locales "cuando quede acreditado mediante memoria justificativa elaborada al efecto que resultan [formas] más sostenibles y eficientes» que la gestión por la propia entidad local o por un organismo autónomo dependiente de ella, «para lo que deberán tenerse en cuenta los criterios de rentabilidad económica y recuperación de la inversión». A tal efecto deberán constar en el expediente el asesoramiento y los informes recibidos, entre ellos el informe del interventor local. Ahora bien, en la práctica puede no ser fácil justificar la mayor sostenibilidad y eficiencia de una forma de gestión directa sometida a derecho privado, sobre todo si se tiene en cuenta que no solo las entidades empresariales y sociedades locales pueden emplear personal en régimen laboral, sino también la propia entidad local matriz y sus organismos autónomos, tal como permite la legislación vigente, excepto para el ejercicio de funciones reservadas a funcionarios, $\mathrm{y}$ como viene siendo habitual en nuestras administraciones locales ${ }^{28}$.

28 Véase hoy el art. 89 y concordantes de la LBRL. Pese a que el art. 92.2 de la misma ley, en la redacción que le dio la citada Ley 27/2013 (LRSAL), dispone que, «con carácter general» los puestos de trabajo en la administración local y sus organismos autónomos serán desempeñados por personal funcionario, la realidad es que prácticamente el $60 \%$ de su personal tiene contrato laboral, según se deduce del Boletín estadístico 
Con posterioridad y por lo que se refiere al sector público estatal, la LRJSP de 2015 expresa con mayor extensión y precisión esa misma preferencia por las formas de gestión de derecho administrativo. Por un lado, el art. 87.4 establece requisitos específicos para el caso de que un organismo autónomo se pretenda transformar en entidad pública empresarial o sociedad mercantil o cuando una entidad pública empresarial se quiera transformar en sociedad, requisitos que no se exigen en los casos opuestos. En concreto, se precisa en aquellos una memoria que, entre otras cosas, justifique que la entidad no puede asumir sus funciones manteniendo su forma originaria, y un análisis de eficiencia. Por otro lado, el art. 114.1 impone para crear una nueva sociedad mercantil estatal que se elabore un plan de actuación, en el que se justifique «que la forma jurídica propuesta resulta más eficiente frente a la creación de un organismo público u otras alternativas de organización», entre otros extremos. Para la creación de una nueva fundación del sector público estatal o la adquisición de ese carácter en forma sobrevenida, el art. 133.1 exige la aprobación por ley, que debe precisar los recursos económicos con que se la dota; y el art. 133.2 dispone que el anteproyecto de ley correspondiente debe ir acompañado de un plan de actuación, favorablemente informado por el Ministerio de Hacienda o la IGAE, que, conforme al art. 92, justifique también que la forma de organización elegida resulta más eficiente que otras que se hayan descartado. En suma, la LRJSP pone nuevos y serios obstáculos, al menos en el plano formal, a la creación de entes del sector público estatal con forma privada, sea ex novo o por transformación o adquisición de entidades preexistentes.

Además, la LRJSP dispone, como ya se dijo, que las entidades públicas empresariales del sector público estatal se financien mayoritariamente con ingresos procedentes "del mercado", lo que limita sin duda el recurso a esta fórmula organizativa. Asimismo reitera algunas precisiones sobre el régimen jurídico aplicable a las sociedades mercantiles estatales (art. 113) y a las fundaciones del sector público estatal (art. 130), subrayando su sujeción a la normativa presupuestaria, contable, de control económico-financiero y de contratación del sector público y no solo al derecho privado; y por lo que se refiere a su personal, que se rige por el derecho laboral, recuerda que le son de aplicación determinadas normas de derecho público, por su pertenencia al sector público (arts. 117.4 y 132.3): así, por ejemplo, los límites presupuestarios que se han venido estableciendo para el incremento de la masa salarial y la reposición de efectivos, o el número y retribuciones máximas del personal

del personal al servicio de las Administraciones Públicas, correspondiente a 1 de julio de 2017, publicado por el Registro Central de Personal. 
directivo y de los máximos responsables de esas entidades, conforme al R.D. $451 / 2012$, de 5 de marzo y disposiciones complementarias, aparte de la ya mencionada aplicación del código de conducta y principios de selección de personal del EBEP, conforme a su disposición adicional $1^{\mathrm{a}}$, y de otras normas muy anteriores, como las de la Ley 53/1984, de Incompatibilidades del Personal al Servicio de las Administraciones Públicas.

Ciertamente, el art. 113 de la LRJSP prevé que «excepcionalmente la ley pueda atribuirles [a las sociedades mercantiles estatales] el ejercicio de potestades administrativas». Previsión un tanto sorprendente, dado que eso mismo se niega con rotundidad para el caso de las fundaciones del sector público (art. 128.2) y porque el mismo art. 113 dispone que aquellas sociedades no pueden disponer en ningún caso de «facultades que impliquen el ejercicio de autoridad pública». Qué ha querido decir el legislador cuando se refiere al ejercicio de «potestades administrativas» que no impliquen el «ejercicio de la autoridad pública» no es cuestión fácil de responder, pues pertenece a los arcanos de una ley tan poco debatida en sede parlamentaria como carente de calidad técnica y precisión conceptual en no pocas de las novedades que aporta ${ }^{29}$. Ahora bien, el

29 Algunas interpretaciones del precepto se remiten a un concepto amplio de «potestades administrativas", entendidas como "poderes unilaterales [que] se ejercen por sus titulares y producen efectos sin necesidad de la concurrencia de voluntad con ningún otro sujeto». Así, de manera expresa, E. Gamero Casado (2015), Desafíos del Derecho Administrativo en un mundo en disrupción, Comares: Granada (págs. 40 y 69-70). También, de manera implícita, C. Chinchilla Marín (2017), «Las sociedades mercantiles públicas. Su naturaleza jurídica privada y su personalidad jurídica diferenciada: ¿realidad o ficción?», Revista de Administración Pública, 203, págs. 1-56 (pág. 23). La consecuencia que ambos autores deducen es similar: por un lado, celebran que se diga en la ley que, cuando ejercen potestades administrativas, dichas entidades privadas o sociedades mercantiles están sometidas a derecho administrativo; por otra, critican que se permita ejercer tales potestades públicas a entidades de derecho privado, pues deberían estar reservadas a las administraciones y organismos de derecho público. Por mi parte, entiendo que hay que diferenciar, como se infiere del art. 113 LRJSP, entre funciones que impliquen ejercicio de autoridad y «otras» potestades administrativas, aunque este no es el término más correcto, pues puede confundirse con el primero. Gamero Casado considera que potestades administrativas son no solo las que se traducen en actos desfavorables que, obviamente, no precisan de la voluntad de un tercero, sino también «los poderes funcionales cuyo ejercicio produzca efectos favorables para los ciudadanos, como el otorgamiento de subvenciones o la adjudicación de contratos administrativos». Pero, a mi juicio, distinguir entre una y otra cosa es esencial. Un acto de autoridad o que implique ejercicio de autoridad es algo inherente y exclusivo del poder público, que solo este puede adoptar y que tiene efectos por la mera voluntad de aquel, pues obliga de manera coactiva. Lo demás son funciones que pueden ser 
criterio de interpretación más lógico lleva a entender que tales "potestades» se refieren a la adopción de «actos de gestión», pues no puede tratarse de «actos de autoridad», como el mismo precepto establece, entendiendo por tales al menos los actos administrativos que limitan el ejercicio de derechos y actividades de los ciudadanos. Lo que en realidad se reconoce es que algunos de aquellos actos de gestión —adjudicación de contratos del sector público, otorgamiento de ayudas o subvenciones...-- que dichas entidades pueden adoptar por determinación de la ley, han de ajustarse a derecho público, como una excepción más a la sujeción de las citadas sociedades al ordenamiento jurídico privado, que es la regla general que establece el mismo art. 113. Son actos de ejercicio de "funciones públicas», así configuradas por la ley, aunque el legislador haya usado equívocamente el concepto de "potestades» para definirlas ${ }^{30}$.

En fin, la LRJSP regula los consorcios en sus arts. 118 a 127, con un carácter igualmente restrictivo. Es una regulación en su mayor parte básica, que fue ya anticipada para los consorcios locales por la Ley 27/2013 (LRSAL) y más en general por la Ley 15/2014, de 16 de septiembre, de racionalización del sector público y otras medidas de reforma administrativa. En el ámbito local, el art. 57.3 LBRL dispone ahora, en consecuencia, que «la constitución de un consorcio solo podrá tener lugar cuando la cooperación no pueda formalizarse a través de un convenio y siempre que, en términos de eficiencia económica, aquella permita una asignación más eficiente de los recursos económicos», debiendo ve-

públicas y estar sometidas a derecho administrativo, porque atienden a fines de interés general y se financian (normalmente) con recursos públicos, pero son similares a las que, en el ámbito privado, pueden ejercer otros sujetos, como adjudicar un contrato o hacer entrega de bienes o recursos sin contraprestación. Creo que, pese a la confusión terminológica, a esto último se refiere el art. 113 LRJSP cuando alude a "potestades públicas» que pueden ejercer las sociedades estatales y que no implican ejercicio de autoridad. Hubiera sido más correcto aludir a esos «poderes funcionales» (en la expresión de Gamero) como «funciones públicas», obviamente sometidas a derecho administrativo.

30 En sentido similar al que aquí se expone, D. Canals i Ametller (2003: 244-247), que utiliza como argumento de autoridad — y sin duda lo es — la opinión de A. Menéndez Rexach (1997), «La aplicación de la Ley 30/1992 a las entidades públicas empresariales», en Valoración de la Ley 39/1992 tras cinco años de vigencia, Cuadernos de Derecho Judicial (pág. 24). Conforme a sus tesis, que comparto, el art. 22.a) LRJSP y el art. 113 LRJSP, como en su día el art. 2.2 LRJPAC, estarían utilizando un «concepto impropio» de potestad administrativa, «que comprende por extensión» toda actividad que se lleva a cabo en régimen de derecho administrativo, de entre las que es necesario diferenciar las que implican ejercicio de autoridad. Al contrario de estas últimas, las otras funciones o facultades públicas (mal llamadas "potestades») se pueden delegar, encomendar o atribuir a entidades que se organizan en forma de derecho privado. 
rificarse que no se pone en riesgo la sostenibilidad financiera de la entidad local de que se trate y del propio consorcio. Según la LRJSP (art. 123), en el caso de los consorcios en que participe la Administración del Estado, su creación debe ser autorizada por ley y para ello debe incorporarse al anteproyecto de ley un plan de actuación informado favorablemente por el Ministerio de Hacienda, en el que, conforme al art. 92 de la misma ley, se justifique que es la opción más eficiente frente a otras alternativas de organización.

Por lo demás, los consorcios son entidades de derecho público y, aunque no se precisa en la LRJSP el régimen jurídico — público o privado- al que someten su actividad, lo que queda remitido a la normativa autonómica aplicable y a sus estatutos (art. 119.1), cabe recordar que podían ser considerados como organismos adjudicadores de contratos públicos ya desde la aprobación de la LCSP de 2007. Y, en cuanto a su personal, que puede ser funcionario o laboral, la Ley citada 15/2014 impuso la gravosa condición de que procediera exclusivamente de las administraciones participantes en el consorcio, exigencia que la LRJSP (art. 121) ha querido flexibilizar, con realismo, permitiendo la contratación directa de personal del consorcio «excepcionalmente», cuando no resulte posible contar con personal procedente de las administraciones consorciadas «en atención a la singularidad de las funciones a desempeñar»; excepción esta que, dada la vaguedad de los términos en que se formula y teniendo en cuenta la experiencia histórica, es de las que parecen destinadas a convertirse más bien en regla.

Por otra parte, cabe recordar que también las comunidades autónomas han aprobado desde el principio de la década su propia legislación de reordenación o restructuración de su sector público. Aunque se trata de una legislación variada en cuanto a su extensión y efectos, que no podemos analizar aquí, predominan en ella las medidas de extinción o disolución de entidades privadas del sector público, o bien su transformación en entidades públicas de diverso tipo, o la determinación de los límites jurídicos a que deben atenerse en materia presupuestaria y de control, de personal y de contratación, entre otras ${ }^{31}$.

\section{OTRAS MANIFESTACIONES EN LA LEGISLACIÓN RECIENTE}

Pero no solo es la influencia del derecho europeo y las medidas derivadas de la crisis económica y de las finanzas públicas las que explican ese reverdecer

31 Para muestra, baste citar la Ley 172011, de 17 de febrero, de reordenación del sector público de Andalucía, que integra o transforma una serie de sociedades mercantiles públicas en agencias u otros entes públicos de diferente tipo. 
del derecho administrativo o, mejor dicho, la recuperación de parte de su ámbito de aplicación perdido. En otros aspectos las novedades legales parecen explicarse más que nada por la voluntad del legislador de reconocer y reconducir la artificialidad que supone muchas veces la utilización instrumental de entidades privadas del sector público, levantando el velo de la personalidad. Varios ejemplos recientes lo demuestran.

Uno de ellos es el que proporciona el art. 35 de la LRJSP, titulado (paradójicamente) «responsabilidad de derecho privado», siguiendo el precedente del art. 144 de la Ley 30/1992: "Cuando las Administraciones Públicas actúen, directamente o a través de una entidad de derecho privado, en relaciones de esa naturaleza, su responsabilidad se exigirá de conformidad con lo previsto en los arts. 32 y siguientes [de la propia LRJSP], incluso cuando concurra con sujetos de derecho privado o la responsabilidad se exija directamente a la entidad de derecho privado a través de la cual actúe la Administración o a la entidad que cubra su responsabilidad». La novedad de este precepto reside en que ordena aplicar el régimen de responsabilidad patrimonial de derecho administrativo cuando la Administración actúa «a través de» una entidad de derecho privado, incluso si la responsabilidad se exige directamente de esta. El alcance exacto de la norma dista de estar claro, pero es evidente que implica el reconocimiento legal de que, cuando la Administración se sirve de una entidad de derecho privado para el cumplimiento de sus fines, es decir, para el ejercicio de actividades y funciones materialmente públicas o la prestación de servicios públicos, los ciudadanos perjudicados por tal actuación están protegidos por el régimen de responsabilidad patrimonial de derecho público, más garantista que el de derecho privado. Algo que, por cierto, ya había concluido la jurisprudencia contencioso-administrativa en algún supuesto ${ }^{32}$.

Podrá discutirse si esa regla se aplica en todos los casos en que causa un daño indemnizable cualquier entidad del sector público, incluidas las empresas públicas cuya actividad es meramente mercantil o industrial, o solo si se trata de las entidades de derecho privado que ejercen funciones o servicios públicos o actividades que no tengan aquella naturaleza. Habrá que aclarar también si, en el caso de que la responsabilidad se exija directamente de la entidad de derecho privado causante del daño, la reclamación correspondiente debe ajustarse a lo dispuesto al efecto en la legislación administrativa (hoy en

32 Véase, por ejemplo, la STS, 3a , de 8 de marzo de 2011 (rec. núm. 1306/2010), que reconoce la competencia del orden jurisdiccional contencioso-administrativo y la aplicación del régimen de responsabilidad patrimonial de derecho administrativo a la Sociedad Estatal Correos y Telégrafos, por el extravío de un envío postal. Otros ejemplos en E. Montoya Martín (1996), Las empresas públicas sometidas a derecho privado, Madrid: Marcial Pons (págs. 553-541). 
día en la Ley 39/2015, de Procedimiento Administrativo Común), y si, como parece deducirse de la letra del precepto, es posible alternativamente formular esa reclamación ante la propia Administración matriz o de tutela. En fin, si la reclamación de responsabilidad es resuelta por una entidad de derecho privado, queda por determinar cuál sería la naturaleza jurídica de su resolución y si sería posible impugnarla en la vía contencioso-administrativa o en la vía civil. Todos estos extremos deberán precisarse por la jurisprudencia, si el propio legislador no los precisa ulteriormente. Pero lo que es indudable es la aplicación de las normas sustantivas del derecho administrativo en tales casos.

Un segundo ejemplo se halla en la modificación de la disposición adicional $16^{a}$ de la Ley General de Subvenciones, que opera la disposición final $7^{\mathrm{a}}$. dos de la LRJSP. La anterior facultad que reconocía aquella disposición a las fundaciones para otorgar subvenciones con el solo límite de los principios de la ley ha sido sustituida por un régimen mucho más riguroso, según el cual las fundaciones del sector público estatal solo pueden conceder subvenciones cuando así lo autorice de manera expresa el Ministerio u órgano al que se adscriben. Además, corresponde a la Administración que financie en mayor medida a una fundación o, en su defecto, a la que ejerza el protectorado de la misma aprobar las bases reguladoras de la subvención y ejercer las funciones relativas al reintegro e imposición de sanciones, las de control y las demás que comporten el ejercicio de potestades administrativas al respecto. Por tanto, a las fundaciones les corresponderán solo funciones de mera gestión de las subvenciones previamente autorizadas. Con lo cual se recupera asimismo la aplicación prácticamente íntegra del derecho administrativo en esta materia y ámbito.

En fin, la jurisprudencia reciente viene atribuyendo en algunos casos la naturaleza de actos administrativos o equivalentes a determinadas decisiones adoptadas por sociedades mercantiles públicas en el ejercicio de funciones típicamente administrativas, como la gestión de bienes de dominio público: por ejemplo, la STS de 17 de mayo de 2012 (rec. núm. 2616/209) ${ }^{33}$.

\section{LA APORTACIÓN DOGMÁTICA DE LA NUEVA LEY DE CONTRATOS DEL SECTOR PÚBLICO}

Pero es la reciente Ley de Contratos del Sector Público, 9/2017, de 8 de noviembre, la que ha venido a ratificar con mayor énfasis y concreción esa

33 Cita y comenta esta sentencia C. Chinchilla Marín (2017: 27), junto con otros pronunciamientos del Tribunal Supremo y del Tribunal Constitucional de los que, con mayor o menor precisión, cabe deducir semejantes conclusiones. 
tendencia de regreso a la aplicación del derecho administrativo. Aparte de que es algo que emana del conjunto de ese extenso (y complejo) texto legal y de los principios en que se inspira, algunos de sus preceptos lo reflejan de manera manifiesta.

Para empezar, el art. 3 aclara algunos aspectos sobre el ámbito subjetivo de aplicación de la ley, despejando las dudas que pudieran derivar de las cláusulas generales de la legislación anterior. Por lo que aquí interesa, se establece que, a efectos de dicha ley, tienen la consideración de administraciones públicas los consorcios (sin excepción), así como otras entidades públicas que, reuniendo las condiciones para ser considerados poder adjudicador, no se financien mayoritariamente con ingresos de mercado, es decir, que no tengan la consideración de productor de mercado conforme al Sistema Europeo de Cuentas (ap. 2). Eso viene a significar que los contratos que adjudiquen los consorcios administrativos o esas otras entidades públicas — entre ellas, no pocas de las entidades públicas empresariales existentes- y estén regulados por la LCSP son contratos administrativos, de acuerdo con el art. 25.1 de la propia LCSP. También se indica sin matiz ni excepción alguna que las fundaciones públicas se consideran poderes adjudicadores a los efectos de la ley (ap. 3). Los contratos que celebren esas fundaciones tienen, pues, carácter privado, pero deben regirse en su preparación y adjudicación por las normas relativas a los contratos firmados por los poderes adjudicadores (art. 26.1 y 2$)^{34}$.

Ahora bien, de acuerdo con los arts. 317 y 318 LCSP resulta que la preparación y adjudicación de los contratos celebrados por los poderes adjudicadores que no tengan la condición de Administración pública se someten a las mismas reglas que los celebrados por las administraciones públicas y ello no solo cuando se trata de contratos sujetos a regulación armonizada, sino el resto de los contemplados en la LCSP, incluidos los límites económicos para firmar contratos menores. No solo eso, sino que según el art. 319, aunque se trate de contratos privados, se les aplican determinadas normas de la LCSP sobre obligaciones en materia ambiental, social y laboral, condiciones especiales de ejecución, supuestos de modificación del contrato, cesión y subcontratación, condiciones de pago y algunas causas de resolución, que están previstas en la regulación de los contratos administrativos. En definitiva, los contratos que firman los poderes adjudicadores que no son administración pública no son contratos administrativos, pero su régimen jurídico se les parece mucho.

34 Lo mismo se predica, por cierto, de los contratos de la entidad Puertos del Estado y de las Autoridades Portuarias, así como de los que deriven de la actividad comercial del Museo del Prado y del Museo Reina Sofía, conforme a las disposiciones adicionales $39^{a}$ y $42^{a}$ LCSP, respectivamente. 
Por lo que se refiere a los contratos que adjudiquen entidades del sector público que no tengan el carácter de poderes adjudicadores — y aquí estamos hablando sobre todo de empresas públicas constituidas para atender a finalidades de naturaleza industrial o mercantil y que se financian mayoritariamente con ingresos de mercado, empresas en las que podría ser público solo una parte del capital - el art. 321 LCSP no se limita ya a ordenar la genérica aplicación de los principios de publicidad, concurrencia, transparencia, confidencialidad, igualdad y no discriminación y a prescribir que se aprueben unas instrucciones internas sobre procedimientos de adjudicación que los garanticen. A eso ańade unas reglas mínimas de directa observancia para cuando no existan tales instrucciones, inspiradas en la regulación general de la propia ley.

Pero lo más relevante de todo, por lo que aquí interesa, es el régimen de nulidad, revisión y recursos contra las decisiones o actuaciones en materia de preparación y adjudicación de contratos que adopten todas aquellas entidades del sector público que tengan la consideración de poderes adjudicadores, ya tengan forma pública o privada de personificación, e inclusive otras que ni siquiera sean poderes adjudicadores.

En virtud del art. 38 de la LCSP de 2017, el régimen de invalidez de los contratos es el mismo para los que celebren las administraciones públicas y los demás poderes adjudicadores, con independencia de que se trate o no de contratos sometidos a regulación armonizada.

En virtud del art. 41.1, se admite la revisión de oficio de los actos de preparación y adjudicación de todos los contratos del sector público que sean nulos de pleno derecho, de conformidad con lo dispuesto en la Ley 39/2015, de 1 de octubre, de Procedimiento Administrativo Común de las Administraciones Públicas (LPACAP) para la revisión de los actos administrativos. Dicha revisión — o, en su caso, la declaración de lesividad de actos anulables- se llevará a cabo por el órgano titular de la administración de tutela si los actos revisables proceden de una entidad del sector público que no tenga la condición de Administración pública (art. 41.3 LCSP), sea poder adjudicador o no.

Por lo que se refiere al régimen de recursos, la posibilidad de interponer el recurso especial en materia de contratación (arts. 44 y siguientes) se limita a determinados actos de preparación y adjudicación de ciertos contratos, conforme a reglas que se aplican por igual a los que se adoptan por las administraciones públicas o por otros poderes adjudicadores (art. 44.1). En todos los casos en que no quepa interponer ese recurso especial, los actos y actuaciones realizadas en los procedimientos de adjudicación de los contratos del sector público son siempre susceptibles de impugnación en vía administrativa, en los términos previstos en la LPACAP. Así es tanto si se trata de actos una entidad que tenga la condición de Administración pública como si es otro poder adjudicador que no tenga esa condición, como — de 
manera significativa - en todos los casos en que lo que se impugne sea una decisión o actuación de una entidad del sector público que ni siquiera tenga la condición de poder adjudicador (arts. 44.6 y 321.5). Obviamente, en todos los casos en que se recurre contra actuaciones de entidades que no sean Administración pública, el órgano competente para resolver el recurso administrativo será el titular del departamento, ente u organismo al que corresponda la tutela sobre aquellas. Es decir, se prevé para todos esos casos un régimen de alzada impropia.

En fin, el art. 41.2 extrae de todo ese régimen de revisión e impugnación de decisiones de entidades del sector público que no son administraciones una consecuencia significativa y muy relevante para la construcción y la evolución dogmática de nuestro derecho administrativo: «A los exclusivos efectos de la presente Ley, tendrán la consideración de actos administrativos los actos preparatorios y los actos de adjudicación de los contratos de las entidades del sector público que no sean Administraciones Públicas, así como los actos preparatorios y los actos de adjudicación de los contratos subvencionados a que se refiere el artículo 23 de la presente Ley».

He aquí que se admite expresamente por el legislador la existencia de actos administrativos de entidades privadas del sector público e inclusive de personas que no forman parte del sector público y son privadas sin más, como algunas de las que pueden adjudicar los llamados contratos subvencionados. No se distingue a tal efecto entre los actos o decisiones preparatorias y de adjudicación de contratos que dicten las entidades privadas consideradas poderes adjudicadores - por ejemplo, todas las fundaciones del sector público- de las que aprueben otras que no tienen ese carácter - por ejemplo, muchas sociedades públicas, incluidas aquellas en que el capital privado quede por debajo del 50 por cien-. Para la nueva LCSP, toda esta actividad contractual tiene un sustrato público, lo que implica que no solo está regida por las mismas o similares normas, sino también que es recurrible en vía administrativa y, obviamente después en vía contencioso-administrativa, una vez agotada aquella. Y, si se trata de actos administrativos impugnables, será difícil no aplicarles en muchos aspectos las reglas generales y la construcción dogmática propia de los actos que figura en la LPACAP: por ejemplo, requisitos de competencia y de procedimiento, límites de la discrecionalidad de decisión, obligación de motivar y notificar, presunción de validez, etc. Con ello el derecho administrativo recupera un ámbito de aplicación del que había sido desalojado hace décadas.

No es que la atribución de la naturaleza de actos administrativos a decisiones adoptadas por entidades del sector público con forma de personificación privada constituya una absoluta novedad. Ya se ha visto cómo algunas sentencias lo venían reconociendo en ciertos casos, tal como sucede, por cierto, 
en ordenamientos próximos al nuestro ${ }^{35}$. Sin embargo, ahora esa conclusión la deduce la propia ley y referida incluso a adjudicaciones de contratos que pueden no tener como finalidad el ejercicio de funciones o servicios públicos, sino también actividades de naturaleza puramente industrial o mercantil, lo que es bastante más discutible. En cualquier caso, es muy probable que la nueva norma legal anime a la jurisprudencia a atribuir también la condición de actos impugnables en vía contenciosa a otras decisiones de sociedades y fundaciones públicas, por ejemplo relativas a la gestión de bienes públicos o al régimen de personal.

\section{PARA CONCLUIR}

Cabe preguntarse, a raíz de lo expuesto, si tiene sentido hoy en día mantener la personalidad jurídica privada de ciertas entidades puramente instrumentales; por ejemplo, las que se crearon en su día para la gestión de infraestructuras y del patrimonio púbico, ya que uno de los objetivos esenciales de su creación fue precisamente eludir los lentos y burocráticos procedimientos de preparación y adjudicación de los contratos públicos. Quizá sería más lógico distinguir con toda claridad, incluso a efectos de la organización del sector público, entre lo que son actividades industriales o mercantiles gestionadas por empresas de capital público u otras entidades, de las actividades de gestión de bienes y de contratos públicos o de prestación de servicios públicos o similares, que son actividades públicas por esencia. Esa es la línea de demarcación que parece deducirse del derecho europeo, como se ha visto: la de las entidades que son productores de mercado y las que no. En consecuencia, sería razonable reservar el segundo tipo de actividades a organismos y entidades de derecho público, cualquiera que fuera su tipología.

Sin embargo, no puede olvidarse que la creación de entidades instrumentales sometidas en mayor o menor medida al derecho privado no solo se explica por la voluntad de responsables políticos y gestores públicos de actuar

35 En Francia, por ejemplo, el Conseil d'État reconoce la naturaleza de actos administrativos a las decisiones adoptadas por organismos de derecho privado en el cumplimiento de misiones de servicio público que implican el ejercicio de prerrogativas públicas desde el ârret Monpeurt, de 31 de julio de 1942, y el ârret Magnier, de 13 de enero de 1961 (véase, por ejemplo, R. Chapus, Droit administratif général, I, Paris: Montechestien, 1992, pág. 400). Sobre ello, F. Moderne (1975), «Decadencia del punto de vista orgánico en la definición de acto administrativo en el derecho francés: los actos administrativos de origen privado", Revista Española de Derecho Administrativo, 4, págs. 3-15. 
con mayor libertad y menor control. Esta es, sin duda, la razón principal en algunos casos. Pero hay también otra, más general, que consiste en la búsqueda de mayor eficiencia y agilidad en la gestión, algo que tiene que ver sobre todo con el régimen económico-financiero y con el régimen de personal. No es lo mismo, desde este punto de vista, sujetar a fiscalización previa cualquier expediente de gasto, con los efectos dilatorios y a veces paralizantes que puede tener, que someter la gestión económico-financiera a un control a posteriori mediante informes o auditorías ${ }^{36}$. Y, por lo que se refiere a la gestión de personal, es obvio que el modelo legal de función pública vigente mantiene una elevada rigidez, a falta de las necesarias reformas, una y otra vez postergadas.

Desde este último punto de vista, el acusado formalismo de los actuales procedimientos de selección de personal en las administraciones públicas, que además se suelen dilatar extraordinariamente en el tiempo, la inexistencia de un sistema de progresión profesional basado realmente en el mérito y el rendimiento, la imposibilidad de retribuir a los empleados públicos en atención a su desempeño individual y teniendo en cuenta criterios más próximos a los del mercado laboral, las garantías casi absolutas de inamovilidad con independencia de la conducta personal y de la situación económica y financiera de la administración o entidad empleadora son, entre otros, factores de inflexibilidad, que hasta ahora solo parecen poder evitarse recurriendo a formas de organización y gestión más próximas a las de las empresas. Cuando el derecho administrativo no evoluciona ni ofrece una respuesta efectiva a estos problemas, la huida hacia el derecho privado de la organización es difícil de contener.

El retorno del derecho administrativo se está produciendo, pues, solo a determinados efectos, sin que con esto se quiera menospreciar su importancia. Al contrario, es positivo en el plano de las garantías de igualdad de los ciudadanos, de la transparencia y del control de los recursos públicos. Pero debe

36 Justo antes de terminar este artículo leo en la prensa (El País, 21 de marzo de 2018) una tribuna firmada por más de doscientos científicos del CIEMAT, titulada «El CIEMAT está al borde del colapso», en la que denuncian los problemas de gestión que está provocando en ese organismo público de investigación (y quizá también en otros) la aplicación de la normativa general de las administraciones públicas y, en particular, la intervención previa del gasto, que dificulta o impide — con retrasos de más de un año para autorizar en ocasiones gastos de no más de 3000 euros - una actuación eficaz en el plano internacional y de colaboración con entidades privadas. Quienes dirigimos o gestionamos grupos de investigación en las universidades hemos padecido también con frecuencia los rigores de una burocracia formal y en la práctica esterilizante. Deben buscarse formas para hacer compatible el control adecuado y puntual del empleo de los fondos públicos con la agilidad de la gestión, evitando la secular dialéctica ente la rigidez y la huida del régimen general. 
combinarse con las reformas que mejoren la eficacia de la actuación administrativa. De lo contrario, sobre todo a medida que se superen las urgencias derivadas de la crisis de sostenibilidad de las finanzas públicas, podríamos ver de nuevo aparecer una tendencia inversa. Quizá, como tantas veces ha sucedido y como ya advertía el profesor Clavero Arévalo hace más de medio siglo, mediante normas singulares aplicables a determinadas entidades, que al final acaban por multiplicarse.

Ojalá se acierte a cohonestar el sistema de garantías de los ciudadanos ante todo ejercicio de funciones materialmente públicas con los requerimientos de una gestión interna ágil y eficaz, lo que no tiene por qué ser imposible, y podamos constatar que el derecho administrativo efectivamente ha vuelto para quedarse. 